\title{
UNIVERSIDADE, JUVENTUDE E RESISTÊNCIA: MEMÓRIA DA REFORMA UNIVERSITÁRIA BRASILEIRA DE 1968
}

\section{Gretha Leite Maia ${ }^{1}$}

\section{Resumo}

O artigo se propõe a investigar as relações necessárias entre a Universidade e a juventude, a partir da afirmação de que Universidade e juventude são protagonistas de transformações sociais, por vezes por meio de atos de resistência. $\mathrm{O}$ artigo investiga as origens da Universidade na Europa Medieval para apontar a permanência de características originais e as modificações que the garantem sobrevida. Investiga a instalação da Universidade no Brasil e o crescimento da população universitária. Em seguida, investiga o conceito de juventude estabelecido na variação de segmento perigoso e sujeito de direitos. A pesquisa articula as duas noções para resgatar o movimento de resistência à reforma universitária brasileira de 1968, no contexto do governo militar e dos Acordos MECUsaid. Trata-se de pesquisa bibliográfica e de caráter memorialista, a partir de uma revisão e literatura. Conclui pela implicação necessária entre Universidade e juventude, desvelando que uma crise na Universidade pode ser causa e consequência de uma crise na juventude.

Palavras-chave: Universidade; Juventude; Reforma; Resistência; Acordos MEC-Usaid.

\section{INTRODUÇÃO}

Algumas criações humanas têm demonstrado uma capacidade de se manterem como entes indissociáveis da própria ideia de uma sociedade. São categorias sem as quais seria desestabilizada a fundação do edifício civilizatório ocidental. A ideia de Justiça, de Democracia, o Direito e o Estado tem demonstrado essa capacidade de sobrevida. A Universidade também parece ter tal potencial, pois que permanece como uma das mais antigas criações da humanidade. Mais recente historicamente, a noção de juventude, assim como a da infância, constituiu-se como referência identitária que ajuda a organizar o corpo social na modernidade, e parece vocacionada ao não-desaparecimento.

Ao propor uma reflexão que envolvesse a Universidade, a juventude e uma proposta de resistência, foram dispostas as seguintes perguntas de partida: há uma relação necessária entre Universidade e juventude? E há uma relação igualmente necessária entre juventude e resistência? Em outros termos, uma crise da juventude é também uma crise da Universidade? E uma crise da Universidade é uma crise da juventude? Para obter respostas

\footnotetext{
${ }^{1}$ Professora Adjunta do Departamento de Direito Processual da Faculdade de Direito da Universidade Federal do Ceará. E-mail: grethaleitemaia@gmail.com
} 
confiáveis, é preciso definir o que se entende, para fins desta reflexão, por Universidade, por juventude e por resistência. Também será preciso dimensionar um recorte espacial e temporal a fim de garantir objetividade à pesquisa. Assim, especificamente será investigada a Universidade e a juventude brasileiras pensadas a partir do episódio histórico mais significativo de resistência da juventude universitária brasileira: os debates em torno da Reforma de 1968.

Desta forma, o artigo foi construído em três partes: na primeira parte foram feitas as considerações sobre a proposta e a vivência de Universidade, desde a sua origem europeia até sua instalação no Brasil; na segunda parte, foram sistematizadas noções de juventude; na terceira parte, põe-se em foco a reforma do ensino superior no Brasil em 1968 e o protagonismo assumido pela população discente da universidade de então. Por fim, as ideias apresentadas foram articuladas com a proposta de ser a Universidade um espaço de resistência e a juventude a protagonista dessa tarefa social. Trata-se de pesquisa bibliográfica, com revisão de literatura e análise das conexões entre Universidade, juventude e resistência no Brasil contemporâneo. Propõem-se como um inventário memorialista, por meio de revisão de literatura, ao qual se acrescenta uma reflexão crítica.

\section{UNIVERSIDADE}

A Universidade é uma invenção da Idade Média europeia. Trata-se de uma forma específica de produção, partilha e apropriação do conhecimento. Determina uma forma escolar do saber, acima de tudo organizada e registrada. Estrutura-se a partir do modelo de hierarquia da Igreja Católica medieval. A dependência do catolicismo assinala seu nascimento, bem como os traços de apego à busca por uma verdade divina, a escolha do trivium e do quadrivium como metodologia de ensino e a predominância do latim e do grego. Este trabalho adotará a perspectiva proposta por Le Goff (2014) de conhecer outra Idade Média, uma Idade Média total, relativa ao intervalo entre o baixo Império Romano e a Revolução Industrial dos séculos XVIII e XIX, que se compreende pelo cruzamento de múltiplas fontes. Nesta perspectiva, buscará identificar que consciência a Universidade medieval teve de si mesma e como se davam as relações entre a Universidade e os poderes públicos no Renascimento, com o objetivo de descobrir mais sobre quem eram os primeiros universitários.

Antes se diga que a Universidade nasceu de um mundo que cultivava o saber em núcleos culturais dispersos, que dispunham de bibliotecas que atraiam homens para uma convergência de saberes (BRAGA, 2006). Daí talvez se herde o que se identifica como a consciência docente, que indica aos professores, desde o medievo, que os métodos e finalidades de seus ensinos e pesquisas são relativamente autônomos. Para nascer, ao final do século XI, a Universidade se ergue aos poucos em torno de concessões monárquicas, bulas papais, chancelas e privilégios, e possíveis intervenções dos Tribunais da Inquisição. Predomina um "agostinianismo" que impõe a crença de que o decisivo é a consciência moral, o aprimoramento do espírito para iluminar a inteligência na busca 
de reconhecer a lei divina eterna. Seus alunos, em geral, não possuíam dinheiro para sagrarem-se cavalheiros do Rei e eram por demais mundanos para a ordenação e o celibato, no seguimento de uma carreira eclesiástica stricto sensu. Havia desde sua criação um perfil para sua população.

Le Goff (2014), ao debruçar-se sobre a nascente Universidade de Paris, indica o conflito entre medicantes e seculares no século XIII como o momento em que os universitários parisienses tomam consciência de si, uma vez que a disputa consistia em afirmar, com os seculares, ou negar, com os mendicantes/franciscanos, a compatibilidade do duplo pertencimento a uma ordem monástica e a uma corporação universitária. Com isso, os seculares se viram obrigados a construir uma base teórica para dar suporte a sua consciência profissional. A questão também separava arte e ofício, conferindo uma especificidade ao trabalho do universitário. Ainda segundo Le Goff (2014, p.248), se "os universitários dos séculos XII e XIII tinham consciência de sua vocação de descobridores, os do século XV se contentam em ser conservadores".

Ao tecer considerações sobre as Universidades e os poderes públicos na Idade Média e no Renascimento, Le Goff (2014, p. 257), afirma que, ao se apresentarem como corporações, as Universidades medievais buscavam um monopólio escolar, isto é, procuravam assegurar "antes de tudo o monopólio da colação de graus que as coloca, principalmente no começo de sua história, em conflito com a autoridade eclesiástica, mas não com os poderes públicos". O que conferia à Universidade nascente no medieval algum prestígio foram, simultaneamente, sua precoce condição de centro de atividades sociais e culturais e a exclusividade na concessão de graus: a licença para ser professor (preceptor), o grau de bacharelado, que tornaria o estudante assistente de um mestre, e o doutorado, reservado para aqueles que podiam pagar a régia festa comemorativa do grau. A Universidade gerava um sistema que se retroalimentava. Como corporação, gozava de privilégios especiais, tais como a isenção de patrulha e de serviço militar, de acordo com o caráter clerical dos universitários.

Outro aspecto ressaltado por Le Goff $(2014$, p. 258) era a forma de remuneração do trabalho docente. Embora haja versão bastante disseminada de que tal trabalho era pago diretamente pelos estudantes (até com presentes na ocasião das provas), os professores profissionais não conseguiam viver dessa coleta: "o essencial de sua remuneração vinha, portanto, junto com benefícios eclesiásticos, salários e rendas que lhes eram concedidos pelas cidades, pelos príncipes e pelos soberanos". Le Goff ressalta que os poderes públicos exigiam o direito de representação ligado ao patronato e, assim, a corporação universitária muitas vezes não gozava inteiramente de um dos privilégios essenciais de uma corporação: o controle e a autonomia de recrutamento.

Se a Universidade no século XV já era conservadora, também se deve reconhecer que contribuiu, como centro de formação profissional, para o adensamento da burocracia que mais tarde se apossaria do Estado. Ao lado deste aspecto utilitário do seu trabalho, a Universidade se firma como grupo econômico de consumidores, havendo um setor específico em que era, ao mesmo tempo, consumidor e produtor: o mercado de manuscritos. 
As universidades formavam, entre a população urbana, um grupo masculino, em sua grande maioria de jovens e celibatários. Segundo Le Goff (2014, p.262), o caráter clerical deste grupo era suficientemente frouxo para que grande número deles não se sentisse tão submisso a certas regras de conduta dos eclesiásticos, especialmente a continência, a sobriedade e a abstenção da violência: pelo contrário, seguros dos privilégios jurídicos que lhes conferiam, se não a impunidade, ao menos sanções menos graves, "um grande número de universitários [e isso, ainda que evidentemente em menor medida, tanto vale para os mestres quanto para os estudantes] se envolvem em atos violentos próprios da idade [...]".

A ideia de pertencimento a um segmento etário parece justificar a expectativa de tumultos protagonizados pela juventude universitária. Le Goff (2014) narra o envolvimento dos universitários nas rixas, nas perturbações noturnas, nas práticas de jogos de azar, na frequência de tabernas e prostíbulos, nascendo o mito da boemia estudantil. Em resumo, como uma instituição fortemente hierarquizada e apegada à tradição, era o local mais propício ao germe do seu contrário. Daí porque se diz que todo Reitor sabe melhor do que ninguém da vocação da juventude para insurgência, revoltas e motins.

Fator que influiu para transformações da Universidade medieval foi a Reforma Luterana e com ela o triunfo do princípio "cujus régio jus religio". As universidades se dividiram em Católicas e Protestantes e tal divisão contribuiu para acelerar a nacionalização ou, antes, a regionalização das universidades. Para Le Goff (2014, p.269), o fato de que o Humanismo se desenvolveu em parte fora das universidades sinaliza como elas foram perdendo o monopólio da cultura e da ciência para outras formas de comunidades de pensadores, estudiosos e pesquisadores, o que teria favorecido a conversão da carreira universitária numa profissão laica. Ao longo do século XVIII, foi fora das Universidades que os pensadores da modernidade puderam elaborar seus pensamentos e enunciar suas descobertas ${ }^{2}$. A Universidade, porém, preservou sua existência por meio de uma capacidade de reorientar-se institucionalmente, com a burocratização do Estado moderno.

Passada a era das revoluções, a reestruturação do Estado, no século XIX, trouxe as universidades para dentro da estrutura do big government, com boas instalações e professores e funcionários integrantes de uma burocracia leiga e nacional. A Universidade definitivamente assume o papel de formar também os burocratas que ocupariam os espaços profissionais dentro da estrutura estatal; deixa de ser uma instituição que se retroalimentava e passa a ter função social relevante. Dentro da Universidade, o incremento na produção de livros impressos permitiu o abandono das práticas de oralidade e memorização, viabilizando condições para a reflexão ${ }^{3}$. A

\footnotetext{
${ }^{2}$ Cf. estudo intitulado "Os filósofos podem a árvore do conhecimento: a estratégia epistemológica da Encyclopédie", in Darnton, Robert. O Grande Massacre de Gatos: e outros episódios da história cultural francesa. Trad. Sônia Coutinho. 2. ed. São Paulo: Paz e Terra, 2015.

${ }^{3}$ Cf., sobre o negócio livreiro no século XVIII na França iluminista, Darnton, Robert. Um inspetor de polícia organiza seus arquivos: a anatomia da república das letras, in O Grande Massacre de Gatos: e outros episódios da história cultural francesa. Trad. Sônia Coutinho. 2. ed. São Paulo: Paz e Terra, 2015.
} 
consolidação do Estado-Nação determinou um modelo de universidade para a Inglaterra, para a Alemanha, para a França, para os Estados Unidos, como projetos nacionais, cuja especificidade escapa a este estudo.

Com a chegada dos europeus na América, várias instituições de transplantaram. O cenário nas Américas distingue os ibéricos entre si no que se refere à instalação de universidades. Em toda a América espanhola houve um esforço em prol da educação formal. A Universidade Nacional Maior de São Marcos, em Lima, no Peru, é a mais antiga no continente americano, criada em 12 de maio de 1551, com curso de Teologia, para formar os noviços na região. A Universidade do México foi fundada em 1553 e havia estabelecimentos similares nos principais centros coloniais hispânicos, embora não existisse um sistema organizado de escolas primárias, voltadas à tarefa de que todos aprendessem a ler e escrever. Na colônia portuguesa, de acordo com Romanelli (2014), o empreendimento educacional foi inicialmente protagonizado pelos jesuítas e objetivava antes de tudo a difusão e a conservação da fé católica, em aliança com o projeto colonizador da Casa Portuguesa. Em 1550, os jesuítas fundam um colégio na Bahia e em 1553 inicia-se o curso de Humanidades. Em todo caso, tais instituições objetivavam ser úteis à causa missionária. Duzentos anos depois, por volta de 1750, o Marques de Pombal entenderia que a educação deveria ser útil para o atendimento dos fins do Estado, expulsando os jesuítas e destruindo o sistema colonial de ensino. Não houve fôlego para que o Estado ocupasse esse espaço.

Apontado como legado desta decisão, o apego da universidade no Brasil ao que se chama cientificismo divide opiniões, pois gerou os Institutos de Ensino Superior, de natureza mais profissionalizante, e que mais tarde seriam reunidos para formar as universidades no Brasil. A fragmentação ou especialização de saberes passou a ser a orientação pedagógica nacional, desde que Dom João instalou, a partir de 1810, as Academias Reais para o estudo da Medicina e das Engenharias, e só depois criando os primeiros cursos de Direito em 1827, com o Brasil já independente. As faculdades nasciam e viviam isoladas e seriam depois reunidas sob uma Universidade. Daí porque a UnB, inaugurada em 1962, representava a realização do projeto invertido: concebida com a intenção de ser o melhor projeto educacional da América Latina, desde o seu nascimento objetivava gerar uma comunidade de pensadores integrados e capazes de diagnosticas problemas e oferecer soluções à sociedade brasileira. De acordo com Sousa Júnior (2012, p.7), a UnB era um projeto de "universidade-semente" capaz de refletir e gerar o desenvolvimento do país: "essa Universidade, necessária para o país, realizaria a conciliação da produção de conhecimento com as necessidades sociais brasileiras, concretizando o sentido utópico transformador da Universidade". Foi objeto do maior desmonte da história da educação brasileira, conforme narrado por Darcy Ribeiro em suas "Confissões".

Considerando que a construção de uma estrutura burocrática federal se iniciou realmente no Brasil com Vargas nos anos 30, é este o período em que as Universidades federais se adensaram, pela federalização de faculdades isoladas que muitas vezes estavam sob o orçamento dos estados, medidas reforçadas no segundo 
governo de Vargas entre 1951/54. Desde os anos 1920, surgem demandas urgentes ligadas à educação. É o período do "inquérito sobre a educação no Brasil" e dos educadores e gestores de educação, como Fernando de Azevedo, Anísio Teixeira, Lourenço Filho e Gustavo Capanema. É também o período de criação da UNE, em 1935, num tempo que a Juventude Integralista e a Juventude Comunista eram as organizações que, em geral, congregavam os estudantes das diversas faculdades. Surgem a USP (1934), a UFRJ (criada em 1920 como Universidade do Rio de Janeiro e nominada de Universidade do Brasil em 1937, adotando o nome de UFRJ em 1965), a UNIFESP (federalizada em 1956), a UFPE e a UFBA (criadas em 1946), a UFC (criada em 1954).

Citando um exemplo de como ocorreu esse processo, de acordo com Martins Filho (1996), em 1944 foi encaminhado ao então Ministério da Educação e Saúde um relatório sobre a refederalização da Faculdade de Direito do Ceará: este é o marco documental da origem da UFC. No mesmo ano, o Ministro foi recepcionado na Faculdade de Direito e provocado por um documento com quase dez mil assinaturas que pleiteava uma Universidade para o Ceará. Um Memorial, preparado em 1953 e que contou com a participação em sua redação do constitucionalista Paulo Bonavides, foi encaminhado ao Ministério da Educação. Em setembro de 1953, Getúlio Vargas envia o projeto de lei que criaria a UFC, que somente concluirá o trâmite ao final da legislatura de 1954. A Lei no 2373/54 criou a Universidade Federal do Ceará. Martins Filho (1996) destaca a participação dos estudantes ao longo de todo o processo.

Ressaltando por fim que foi a LDB de 1961 que determinou a participação dos estudantes nos colegiados e demais instâncias deliberativas das Universidades, antes da pesquisa de memória sobre os episódios de reforma de 1968, será investigada a concepção de juventude como um dos argumentos deste estudo.

\section{JUVENTUDE}

A noção de juventude assume uma forma definida quando, de acordo com Savage (2009, p.11), os americanos começaram a usar a palavra teenager para descrever uma categoria de jovens com idade entre 14 e 18 anos. Desde o início foi um termo de marketing que refletia o poder de consumo recentemente visível no adolescente; assim, "o fato de que, pela primeira vez, os jovens se tornaram um público-alvo também significava que eles tinham se transformado num grupo etário específico, com rituais, direitos e exigências próprios". $\mathrm{O}$ autor realiza então, a partir daí uma pesquisa de regresso ao que chama de pré-história do teenager, enquadrada nos intervalos entre os anos 1875 e 1945.

Para a conformação desse conceito, vários aspectos convergiram. A Europa fornece seu referencial de 
juventude na imagem dos românticos e da juventude revolucionária do fim do século XVIII ${ }^{4}$. Em meados do século XIX já se registram, nos Congressos criminalistas, a preocupação com a delinquência juvenil (OLMO, 2004, p.85 e ss). A organização de um exército profissional com a sedimentação do Estado-nação também teve impacto na conformação da ideia de juventude. Savage (2009, p.33) reporta o interesse das organizações armadas em recrutar os jovens, identificando a fase dos 18 aos 24 anos com o melhor grupo etário para formar um exército que com facilidade se despediria da vida "sem angústias" por não estarem ainda presos às obrigações da vida adulta civil, ou seja, prontos para matar e morrer.

Por outro lado, este movimento de identificação também atribui um papel social ao jovem. Os estudos de juventude realizados nos anos 1960 e 1970 são referência histórica da preocupação das ciências sociais com a juventude ${ }^{5}$. Esses estudos levaram a construção de uma pauta de políticas públicas específicas para a juventude, abandonando-se o paradigma dos jovens como um problema e da juventude como uma passagem, para a compreensão da juventude como um estado psíquico de comprometimento com um sentimento amplo em relação à capacidade de mudar a sociedade, e de que, ademais, a juventude nunca acaba, pois nela estão os traços mais profundos da personalidade, que nos acompanharão por toda a vida.Sendo objeto de investigação de vários saberes, como a Sociologia e a Psicologia, no Direito a compreensão da Juventude também possui uma trajetória que vai da compreensão de “juventude perigosa” à categoria “juventude sujeito de direitos”.

Conforme Mattos, Teixeira e Osório (2008), ao fazer um levantamento histórico sobre a participação política da juventude brasileira nas diferentes épocas, encontram-se os primeiros estudos nos anos 1960, com a participação dos jovens nos movimentos estudantis; nos anos 1980 os jovens foram considerados individualistas e indiferentes à atuação política; mas nos anos 1990 houve uma retomada dos interesses nas atividades coletivas, acentuadamente na esfera cultural; no início do século XXI, a modalidade de participação apontada por pesquisas, mostra uma juventude mais sintonizada com sua realidade: são ações grupais comunitárias e voluntárias, muitas vezes apoiadas por instituições religiosas, associações de bairros e organizações não governamentais.

Para alcançar o estudo sobre o movimento de resistências à reforma universitária em 1968 no Brasil, é preciso que neste estudo se verifique, ainda que de forma superficial, os chamados movimentos de massas do século XX, e se faça, também, uma parada histórica no ano de 1968, especialmente para revisitar o famoso "Maio de $1968 "$.

O fascismo, movimento de massas que varreu o Ocidente na primeira metade do sec. XX, entendia a

\footnotetext{
${ }^{4}$ A literatura é instrumento poderoso na reconstrução destas imagens: de "Os Sofrimentos do jovem Werther", de Goethe, publicado pela primeira vez em 1774, passando por Marius e seus amigos ABC, no qual se inclui o revolucionário Enjolras, de "Os Miseráveis", de Victor Hugo, publicado pela primeira vez em 1862.

${ }^{5}$ Há um ramo da Sociologia com foco específico na Juventude, tendo como referência os seguintes estudos: BRITTO, Sulamita. Sociologia da juventude I: da Europa de Marx à América Latina de hoje. Rio de Janeiro: Zahar, 1968; DAVIS, Allisonet
} vol.11, nº. 02, Rio de Janeiro, 2018. pp. 693- 712 
cidadania como a participação em cerimônias de massa de afirmação, conformidade e homogeneização. Segundo Almeida (1982, p.21), desde o primeiro dia de governo nazista na Alemanha estava assinada a sentença de morte para o movimento operário, cujas organizações seriam pulverizadas pela "armadilha do fascismo, que levou à liquidação total da força acumulada pelo movimento operário durante decênios". Para Savage (2009, p.279), os nazistas subiram ao poder "evocando uma abstração de juventude como um agente ativo de mudanças e realmente mobilizando os jovens por meio da mística do conflito, ação e pertencimento". Os grandes desfiles eram destinados a influenciar as emoções dos jovens descontentes. No fim de 1933, quase 3,5 milhões de jovens alemães ingressariam na Juventude Hitlerista, o que corresponde a quase metade da população jovem da Alemanha de então. Tal adesão, prossegue o autor, devia-se em parte ao sistema de coerção montado pelo novo regime, mas os nazistas também aproveitavam o "antagonismo entre gerações" como argumento de adesão e convencimento.

As estratégias preferidas de convencimento do fascismo foram a intimidação e o medo. Antes de chegar ao Reichstag em 1930, o partido nacional socialista não era considerado um partido político sério, mas pouco mais que um grupo de terroristas marginal. Segundo Paxton (2007, p. 214), uma das chaves do sucesso de Hitler foi a sua disposição para cometer assassinatos. Por isso, é equivocada a noção de que bastava apenas o líder carismático para arrastar as multidões. Segundo Paxton (2007), todas as gerações de estudiosos do fascismo notaram que esses regimes se baseavam em algum tipo de pacto ou aliança entre o partido fascista e as poderosas forças conservadoras. De acordo com Paxton (2007, p.198), no início da década de 1940, o social-democrata refugiado Franz Neumann afirmou, em sua obra clássica Behemoth, que "um 'cartel' formado pelo partido, pela indústria, pelo exército e pela burocracia, governava a Alemanha nazista, unidos apenas pelos objetivos do lucro, poder, prestígio, e principalmente medo".

Muitas são as imagens do fascismo. Talvez por ser a mais explicitamente visual de todas as formas políticas, o fascismo muitas vezes é evocado pelo senso comum na figura de um ditador discursando para uma multidão em êxtase e fileiras de jovens militarmente disciplinados desfilando em paradas. Efetivamente, segundo Paxton (2007, p.234), "os regimes fascistas lançaram-se à construção do novo homem e da nova mulher (cada qual na esfera que lhe era própria)". A desafiante tarefa que competia aos sistemas educacionais era a de fabricar "novos" homens e mulheres, que seriam simultaneamente lutadores e súditos obedientes. Se os sistemas educacionais dos estados liberais, além da sua missão de auxiliar os indivíduos a realizar seu potencial educacional, já tinham o compromisso de moldar seus cidadãos, os estados fascistas puderam utilizar os quadros e as estruturas educacionais já existentes, introduzindo apenas uma alteração na ênfase e passando a privilegiar os esportes e o

alii.Sociologia da juventude II: para uma sociologia diferencial. Rio de Janeiro: Zahar, 1968; e COHEN, A. Ket alii.. Sociologia da juventude III: a vida coletiva juvenil. Rio de Janeiro: Zahar, 1968. 
treinamento físico militar. Assim, algumas das funções tradicionais da escola foram absorvidas pelas organizações paralelas do partido, tais como os movimentos de juventude de filiação obrigatória: "nos estados fascistas, todas as crianças eram automaticamente matriculadas em organizações do partido, que estruturavam suas vidas desde a infância até a universidade" (PAXTON, 2007, p.234).

Têm-se então mais uma das viragens no propósito da Universidade. De instituição conservadora no século XV, concorre como formadora da inteligência do século XVIII, em seguida torna-se a "educadora do cidadão" do projeto de Estado-nação, e, pelo fascismo, é entendida como sendo parte integrante de um projeto de formação integral do "novo homem e da nova mulher" nos projetos totalitários do início do século XX, tendo como alvo principal a juventude. Neste último cenário, a relação necessária entre Universidade e juventude está na superfície do projeto político e torna-se visível e inquestionável.

Por sua vez, em um balanço dos 40 anos do "Maio de 68", Morin (2010, p.29) o definiu como uma revolta plurinacional de estudantes, que acontece em países tão diferentes quanto os Estados Unidos, a Alemanha, o Egito, a Polônia; para o sociólogo francês, de certo modo, no mundo todo se vê esse movimento estudantil, já nos anos 1960, na Califórnia, que se "manifesta por meio de uma cultura que viria a se chamar contra cultura, tentativa dos jovens de fazer uma cultura diferente da do mundo em que viviam, criando comunidades". Segundo Morin (2010), nos anos 60 do século XX aconteceu uma verdadeira expansão dos limites do conhecimento, alterando a visão que as pessoas tinham do mundo ao seu redor e do próprio universo. A ascensão da ecologia, novas descobertas da astronomia, o declínio das metanarrativas e das explicações totalizantes veiculadas na utopia comunista e, ao mesmo tempo, o abalo na crença do progresso impulsionado pelo capitalismo, concorreram para minar o sentimento de esperança entre os humanos, instalando uma crise do progresso que se traduzia numa crise de futuro.

Por outro lado, Fonseca Neto (2007, p.65) ressalta o aumento expressivo do contingente estudantil no pós-guerra como causa dos movimentos, conforme os números trazidos por Hobsbawn: de cem mil na França em 1945, a população universitária era de 651 mil em 1968 e "ir para a Universidade deixou de ser um privilégio que, por si só, deixava alegre o estudante”. Ao mesmo tempo, instalava-se uma recessão econômica que levou à Universidade na França a um período de austeridade, no qual a preocupação com a administração tornou-se mais importante que as questões didáticas. Há ainda outro fator revolucionário: a ida das mulheres para a Universidade a partir do segundo pós-guerra, ampliando exponencialmente o movimento feminista, de caráter insurgente ou subversivo da ordem patriarcal.

Maio de 68 foi, essencialmente, uma revolta de jovens que investiram contra a autoridade, qualquer que fosse. Pode-se mesmo falar de uma teoria francesa pós-68, sintetizada em estudo de Lotringer (2010). Tal teoria objetivava desenvolver estratégias de jogar o capitalismo contra ele mesmo, a fim de libertar o ser humano da 
lógica da alienação do capital. Lotringer (2010) denuncia a emergência da sociedade do simulacro, no rastro da cultura de massas, a ritualização cotidiana do espetáculo, os micropoderes e biopoderes de que fala Foucault, e a aceleração da técnica e do tempo, que geram uma distopia desterritorializante, impedindo a compreensão do sentido das coisas que nos rodeiam.

É preciso indagar de que forma podem ser percebidos reflexos desse movimento no Brasil. De maneira geral, o século XX foi um cenário rico em termos de desenvolvimento e atuação política, por meio de partidos políticos e sindicatos, bem como outras formas associativas como "centros", "uniões" e "ligas", nas quais a participação da juventude era possível. Segundo Moraes Filho (1988, p.36), "em meio à agitação, logo no dia seguinte da República, surgem os primeiros partidos operários e socialistas do Brasil, mas de cunho reformista do que propriamente revolucionário". Mas a efemeridade foi a característica de praticamente todos estes grupos: surgiam, lançavam manifestos e desapareciam logo depois de alguns meses ou um par de anos. Com existência legal efêmera na primeira década de existência, o Partido Comunista Brasileiro - PCB significou a associação dos brasileiros ao clube mundial dos revolucionários, em 1922. Em 1937 foi fundada a UNE.

Até os anos 1950, entretanto, não é possível falar de movimento estudantil organizado no Brasil simplesmente pela ausência de uma população universitária que somente foi adensada a partir de então, com a instalação das Universidades no Brasil ocorridas na primeira metade do século XX. A juventude, que se organizava em torno dos movimentos comunista e integralista nos anos 1930 e 1940 para exercer uma atividade política, vai se encontrar nas recém-instaladas Universidades, dando impulso a um movimento estudantil que uniria grupos até então tão atomizados quanto a estrutura de ensino superior brasileira. A partir daí, há uma rica memória do movimento estudantil brasileiro, que será analisado no próximo item.

\section{RESISTÊNCIA: MEMÓRIA DA REFORMA UNIVERSITÁRIA DE 1968}

É no período que compreende os anos 1950 e 1960 que se define, no Brasil, a estrutura que o ensino superior adotará nas décadas seguintes. O regime militar instalado em 1964 traçou uma política de recuperação econômica e, de acordo com Romanelli (2013, p.202), constatou-se "uma aceleração do ritmo do crescimento da demanda social de educação, o que provocou, consequentemente, um agravamento da crise do sistema educacional, crise que já vinha de longe". Essa crise acabou por servir de justificativa para a assinatura de uma série de convênios entre o MEC e seus órgãos e a Agency of Internacional Development (AID), para assistência técnica e cooperação financeira à organização do sistema educacional brasileiro. Esse período é conhecido como dos "Acordos MEC-Usaid", marcado por medidas legais que reformaram o ensino superior a partir das orientações técnicas da AID, por meio da Comissão Meira Matos. Os acordos MEC-Usaid, ao provocarem protestos de todos os lados, teve como efeito o agravamento da crise educacional que se arrastava desde os anos 
1950. De acordo com Romanelli (2013, p.203), a Comissão Meira Matos tinha um duplo objetivo: "atuar como interventora nos focos de agitação estudantil e estudar a crise em si, para propor medidas de reforma". Sob este último aspecto, entretanto, o relatório que a comissão apresentou nada mais fez do que reforçar as propostas originárias dos Acordos MEC-Usaid. Quanto aos "focos de agitação estudantil”, foram se constituindo como uma força legítima de resistência, ao lado da resistência docente.

O movimento estudantil brasileiro, nos anos 1950 e 1960, caracterizava-se como modelo de movimento social verticalmente organizado e apresentava como traço essencial o monopólio institucional da representação. Oficializado segundo o modelo dos sindicatos, o movimento estudantil se estruturava verticalmente: o Centro Acadêmico era o órgão oficial da faculdade; seu presidente tinha assento no Conselho Departamental e a filiação dos estudantes era automática; em Universidades oficiais, o Diretório contava com alguma verba, franquia postal e o direito ao timbre com as armas da República. A União Nacional dos Estudantes - UNE - contava com sua parte no orçamento governamental. Esse tipo de organização fazia com que a UNE representasse os 100 mil universitários da época.

De acordo com Guilhon de Albuquerque (1977), as manifestações envolvendo a reforma universitária de fins dos anos 1950 mobilizam os estudantes universitários brasileiros, iniciando a trajetória de um movimento que só vai tomar forma completa na década seguinte. Em 1960, no Brasil havia dez universidades federais, seis estaduais, oito particulares e três rurais. Em 1961, os estudantes reivindicavam ampliar sua participação no poder, período em que ocorre a renúncia de Jânio Quadros. Martins Filho (1996) registra um intenso movimento dos estudantes durante o ano de 1962 para efetivar a participação dos estudantes nos órgãos colegiados das Universidades, conforme previsão da LDB de 1961. A movimentação incluía paralisação das atividades didáticas, com ocupação das Universidades pelos grevistas. Sob o argumento de preservação do patrimônio público da União, muitas vezes o Comando Militar era informado das movimentações pelos dirigentes das Universidades. No Rio de Janeiro, em Belo Horizonte e em Fortaleza, os gestores estavam convencidos de que somente o Exército se encontrava em condições de assegurar a manutenção da ordem no meio universitário. Efetivamente, Martins filho (1996, p.130) registra que no dia 27 de julho de 1962, todas as dependências da Universidade Federal do Ceará "inclusive o Clube dos Estudantes Universitários, já estavam ocupadas pelas tropas do Exército", episódio que contou com a participação direta do General Castello Branco, então Diretor Geral de Ensino do Exército. Tal narrativa é exemplificativa das demais.

Desde 1962, os estudantes formulavam a proposta de uma reforma universitária, uma vez que, de acordo com Fonseca (2007, p.98), para eles a Universidade estava alienada da realidade brasileira, sendo "uma forte aliada do capitalismo selvagem e fator de manutenção da classe dominante". Propunham uma reforma que pusesse a Universidade a serviço das massas populares, refletindo a consciência nacional e popular da realidade brasileira, 
influenciados pelas propostas de Paulo Freire de uma educação libertadora. Há uma intensa produção de atividade nos CPCs, os Centros Populares de Cultura.

Por sua vez, a celebração dos acordos MEC-Usaid iniciou uma ampla reforma do ensino brasileiro em muito contrária às pretensões formuladas nos anos anteriores. Os estudantes pleiteavam ampliação das vagas e do número de professores nas Universidades públicas, com aumento de verbas e recursos, com a criação de ciclos básicos para a integração de toda a universidade e extinção das cátedras para uma universidade crítica, livre e aberta. Ao invés disso, o discurso da reforma tem outro tom: visava a eficiência, modernização e flexibilidade administrativa; a universidade seria organizada dentro de um modelo empresarial e burocrático com a missão de ser eficiente; as matérias filosóficas mais reflexivas se tornaram optativas e abriram-se os caminhos para as escolas superiores particulares. De acordo com Romanelli (2013, p.218), o que predominava nos acordos MEC Usaid eram os programas para o ensino superior: "o esquema de reformulação estrutural das Universidades é proposto de forma bastante clara e visa a uma dependência direta das instituições dos países subdesenvolvidos às instituições americanas de ensino superior".

Romanelli cita as afirmações de R. Atcon quanto a "conseguir a formação do espírito cívico e da consciência social, conforme os ideais de desenvolvimento pacífico (destacado por Romanelli) de respeito aos direitos humanos e de justiça social" (ROMANELLI, 2013, p.219). Para a autora, de acordo com tal concepção, não caberia à Universidade nenhuma ação inovadora, revolucionária, mas somente acomodadora, atribuindo à Universidade uma missão conservadora. Ao criticar os educadores brasileiros, os princípios que orientavam a reforma justificavam-se no fato de que até então, no Brasil, os educadores não tivessem conseguido impor à sociedade o seu ponto de vista, porque não teriam surgido pensadores educacionais no Brasil com uma clara compreensão dos problemas nacionais. Tal pressuposto revela-se infundado, diante de uma rápida incursão histórica em torno dos educadores brasileiros do século XX. Ademais, conforme Costa (2015a, p.232), Atcon partia do pressuposto preconceituoso de que "o fato de o pessoal da Universidade estar ligado aos cânones do serviço público era responsável por todos os males que recaiam sobre a Universidade brasileira” e assim o projeto Atcon sugeria "como primeiríssima tarefa de reformulação universitária no Brasil a desvinculação do pessoal docente e administrativo dos canais do serviço público".

Os anos de 1963/64 caracterizam a luta pelo poder e a partir de 1964 inicia-se a fase da luta contra o poder. Martins Filho registra uma intensa preocupação com a reação dos estudantes no $1^{\circ}$ de abril de 1964, tendo ocorrido em 02 de abril a ocupação do Clube dos Estudantes Universitários da Universidade Federal do Ceará pela polícia. A Lei Suplicy (Lei no 4464/64) tornou ilegais as atividades políticas estudantis. Ilegal e com sua sede tomada e interditada pela polícia, a UNE continua a atuar clandestinamente. A Lei Suplicy dispunha sobre os órgãos de representação dos estudantes, sendo seguido pelo Decreto Lei no 228, de 1967, que, ao art. 11 
estabelecia ser vedada aos órgãos de representação estudantil qualquer ação, manifestação ou propaganda de caráter político-partidário, racial ou religioso, bem como incitar, promover ou apoiar ausências coletivas aos trabalhos escolares; no parágrafo único lia-se que a inobservância do artigo acarretaria a suspensão ou a dissolução do DA ou do DEC.

Em 1967, vieram as reformas da representação estudantil, eliminando-se a antiga estrutura de âmbito nacional, mediante determinação de que os órgãos de representação discente se limitassem ao âmbito exclusivo de cada Universidade, mantidos os diretórios acadêmicos para cada unidade e o Diretório Central dos Estudantes (DCE) para cada Universidade. Com isso, eliminou-se a coordenação nacional do movimento estudantil levada a cabo pela ex-União Nacional dos Estudantes, que havia alcançado, nos últimos anos anteriores ao regime militar, uma força política considerável. Os relatórios derivados das comissões instituídas pelo governo militar para emitirem pareceres sobre as reivindicações, teses e sugestões referentes às atividades estudantis, concluíam pela existência de uma "crise de autoridade no sistema educacional" (ROMANELLI, 2013, p.230). Chegou-se a propor que fosse revista a concessão da autonomia administrativa e disciplinar nas Universidades conferidas pela LDB de 1961, bem como o modelo de eleição dos Reitores e Diretores, que deveriam ser indicados pelo presidente da República, independente de indicação ou consulta às Universidades. Somente para ilustrar, cite-se que nestes documentos já se inscreviam propostas para a instituição de cobrança de anuidades do ensino superior "como forma de obter mais justiça social", que ainda divide a sociedade brasileira 50 anos depois, e a instituição de um vestibular unificado, que viria a ser uma realidade com a instituição do sistema ENEM/SISU a partir da adesão das Universidades desde 2011.

De acordo com Romanelli (2013, p. 227), com tais propostas "o governo acabou por ensejar uma radicalização total do movimento estudantil liderado pela esquerda, lançando-o, de uma vez por todas, na luta político ideológica que passou a existir na clandestinidade". Motta (2014, p.95) registra igualmente que "apesar dos esforços do governo para aquietar os estudantes, fosse pela via repressiva, fosse por ações integradoras, a rebeldia explodiu em 1967-68", sendo foco principal dos movimentos a "denúncia da desnacionalização da educação implicada nos acordos MEC-Usaid". Neste cenário, em março de 1968, durante uma manifestação estudantil, no restaurante universitário Calabouço, o estudante Edson Luiz foi morto pela polícia, provocando uma passeata de protesto que entre para a história como a passeata dos cem mil.

Para Motta (2014, p.96), a adoção do tom antiamericano que dominava os discursos estudantis significa que "os jovens brasileiros, à sua maneira, ecoavam também os protestos contra a intervenção no Vietnã, tema que mobilizava a atenção do mundo”. Em 1968, acontece também o Congresso da UNE em Ibiuna, com cerca de mil estudantes presos, envolvidos especialmente com a resistência à reforma universitária de 1968 O crescimento da audácia estudantil, nas palavras de Motta (2014, p.96), levou a episódios de ocupação de dependências 
universitárias para pressionar o governo ou protestar contra dirigentes universitários, como nos casos ocorridos na Faculdade de Filosofia da UFRGS, em junho de 1968, na Universidade Federal do Pará em agosto, nas Faculdades de Medicina e de Ciências Econômicas da UFMG, e a invasão da Reitoria da USP, em junho de 1968: "nessas ocasiões, os estudantes demonstraram poder de mobilização e agressividade, o que, combinado à ocorrência das grandes passeatas e confrontos de rua, com muitas mortes provocadas pelos choques com a polícia, levou os órgãos de repressão a temer pela perda do controle da situação". Fechado os canais democráticos, desenvolve-se no Brasil a guerrilha urbana, protagonizada por grupos como Val-Palmares e o MR-8, com a presença majoritária de jovens. A clandestinidade e os desaparecimentos, autoexílios e mortes perpetuaram-se por toda a década de 70 .

O anteprojeto elaborado pelo Grupo de Trabalho da Reforma Universitária (GTRU) transformou-se na Lei no 5540/68, que fixava as normas de organização e funcionamento do Ensino Superior, sendo produzido também por esta comissão o Decreto Lei no 477, de 11 de fevereiro de 1969, direcionado à contenção do protesto estudantil. Ao minimizar a representação estudantil, ampliavam-se a mentalidade empresarial dos tecnocratas no campo da educação superior pública e as medidas de exceção de um governo que tendia para a fase mais aguda da ditadura, estabelecendo um cenário de desenvolvimentismo, eficiência, produtividade, de um lado; controle e repressão de outro. O Decreto-lei no 477 , de fevereiro de 1969, cuidava exclusivamente do aspecto repressivo da ação governamental e é produto da convicção de que o movimento estudantil era um dos pontos críticos da crise do ensino superior. Depois de feitas a análise das entidades consideradas subversivas, concluiu-se pela "inexistência de uma liderança democrática autêntica" e propôs-se a implantação de cursos de lideranças promovidos pelos órgãos oficiais do MEC (ROMANELLI, 2013, p.231). O Decreto Lei no 477 disciplinava a atividade docente, discente e administrativa e proibia toda e qualquer manifestação de caráter político ou de protesto no âmbito das universidades brasileiras. Com isso, suprimia as reivindicações por mais vagas e verbas para a universidade e eliminava as chances de resistência às reformas produzidas sob a orientação dos Acordos MEC-Usaid.

Discorrendo sobre a sobrevida do modelo proposto pelo MEC-Usaid, Costa (2015a) lembra seu caráter tecnológico, privatizante, pseudodemocratizante e economicista, subordinando a educação aos interesses do mercado. Em um trabalho de recuperação da memória, Costa narra que o projeto encontrou séria oposição nos meios universitários, que questionaram o porquê de o governo ter considerado necessário recorrer a uma colaboração com os Estados Unidos contando o Brasil com tantos educadores competentes. Buscando, portanto, razões na política adotada pelos EUA no segundo pós-guerra, Costa (2015a, p.225) aponta que a crescente rivalidade com a URSS fez com que "todos os movimentos revolucionários ou reformistas do mundo passassem a ser vistos como conspirações movidas pelo comunismo internacional”. Assim, a recepção dos acordos projetava o 
clima instalado pela Guerra Fria: "os que se opuseram ao MEC-Usaid foram imediatamente tachado de comunistas e agitadores; os que o apoiavam forma vistos por seus opositores como oportunistas ou entreguistas" (COSTA, 2015a, p.230). Era a projeção de uma política pensada em termos de inimigos, não de opositores.

A despeito do clima de repressão, os debates em torno da reforma geraram grande mobilização entre professores e alunos, conforme registrado por Costa (2015a). As divergências ultrapassaram os muros da Universidade e ganharam as ruas: manifestações estudantis sucederam-se num ritmo crescente, sempre acompanhadas de violência policial; aos protestos estudantis somaram-se as primeiras manifestações de guerrilha. Ao narrar sobre seu processo de cassação na USP, Costa (2015b) enfatiza o período que se inicia em 1960 como de grande mobilização no país; o expediente de criação do parlamentarismo para que João Goulart assumisse a presidência da República manteve a população mobilizada. Costa (2015b, p.281) afirma que "a Universidade foi chamada a participar dos debates que então se travavam e muitos se organizavam para defender o governo, visivelmente ameaçado por uma conspiração militar". Deposto Goulart, iniciam-se as aberturas dos Inquéritos Policiais Militares, os temidos IPMs, que muitas vezes concluíam pela aposentadoria compulsória do docente. Costa (2015b, p.281) conta que "de um dia para o outro, atividades até então legítimas viraram crime contra a segurança nacional: participar de reuniões em favor de presos, criticar o governo, ler Marx, defender ideais nacionalistas". A professora reafirma a instalação de um clima de suspeição e denúncia dentro da Universidade, onde os agentes policiais circulavam livremente, conforme já se colheu das narrativas de Martins acima referidas.

Para Costa (2015b), o estopim da crise foi à tentativa de reforma da Universidade em alinhamento com as orientações dos Acordos MEC-Usaid. A professora Emília Viotti da Costa, de acordo com o Relatório Brasil: Nunca Mais (1985, p.137), "sofreu especial perseguição durante as perseguições, iniciadas com IPM no Quartel General do II exército, sendo acusada de propaganda subversiva”. Tendo sido convidada para dar a aula inaugural da Faculdade de Filosofia, Ciências e Letras no ano de 1968, escolheu como tema a reforma universitária e fez críticas ao projeto MEC-Usaid. Como a conferência foi publicada na revista do grêmio da Faculdade de Filosofia e reproduzida em documentos estudantis de diversas entidades no país, chegaram novos convites para falar sobre o tema. Relata a professora que fez quarenta palestras em várias universidades até que foi convidada, juntamente com José Dirceu, então presidente do grêmio da FFCL, a participar de um programa de televisão para debater a reforma com o ministro Tarso Dutra: "mais tarde, atribuí minha aposentadoria em parte a esta entrevista" (COSTA, 2015b, p.282).

Enquanto os professores organizavam comissões e documentos, o movimento estudantil crescia e se radicalizava, desencadeando respectiva repressão na Universidade: "alunos, suspeito de envolvimento, eram arrancados das salas de aula diante dos olhos atônitos de professores e colegas e levados por soldados sob mira de metralhadoras" (COSTA, 2015b, p. 282). Chamada para depor em um IPM que investigava atividades 
subversivas no Departamento de História da USP, a professora Emília Viotti foi aposentada, por meio de uma lista que incluía vários outros colegas. $\mathrm{O}$ clima de insegurança e irracionalidade a levaram a sair do país, indo para os EUA e lá permanecendo até 1999. Costa (2015a) conclui que o espectro do MEC-Usaid continua a assombrar o país, sugerindo que se os governos militares não completaram sua implementação talvez isso tenha se dado pelas resistências que se lhe foram opostas.

Por fim, convém narrar o que Motta denomina o auge da manifestação da força estudantil, com a ocupação do prédio da Faculdade de Filosofia, na Rua Maria Antônia, a partir de agosto de 1968. A princípio a ocupação foi tolerada, uma vez que as lideranças estudantis decidiram pela ocupação para garantir suas reivindicações, inclusive em relação à paridade e à reforma universitária, até que ficou claro que a ocupação era uma maneira não só de protestar contra a violência policial, mas também de mostrar a força do movimento estudantil. Segundo Motta (2014, p.98), "durante algumas semanas, a faculdade e a rua viveram um clima de "Maio de 1968", em que não faltaram algumas barricadas". O confronto direto envolveu estudantes de diferentes orientações ideológicas, pois que nas cercanias ficava o prédio da Universidade Mackenzie, "reduto de militantes de extrema direita incomodados com a vizinhança de uma experimento, que, aos seus olhos, parecia um verdadeiro soviete de estudantes" (MOTTA, 2014, p.98). A polícia, ansiosa para resolver o problema da ocupação, deixou que o confronto direto tivesse lugar entre os estudantes, deixando um morto, vários feridos e alguns carros incendiados: "a polícia aproveitou-se do conflito e fechou o prédio da Faculdade de Filosofia da USP, para impedir o retorno dos ocupantes", livrando-se do problema. As aulas somente foram retomadas no início de 1969.

Depois do AI-5, a repressão aumentou. Militares ocuparam o Conjunto Residencial da USP, que ficou sob intervenção por dois anos. Motta registra ainda o mesmo clima na UFRJ: desagradável, quase fúnebre. Se desde 1962 os militares eram chamados a ocupar dependências das Universidades e desde 1964 já havia espiões nos campus e uma forte sensação de vigilância, a partir de 1969 a situação se agravou bastante: "o propósito de aterrorizar os contestadores nos meios acadêmicos, um dos objetivos do AI-5, foi alcançado, pelo menos nos primeiros tempos" (MOTTA, 2014, p.151). Toda uma geração de líderes estudantis foi desarticulada e perseguida. O Decreto 477 daria conta de concluir a limpeza: listas negras eram produzidas para impedir matrícula e mesmo contratação como professores de ex-alunos subversivos; além de desligados, os estudantes punidos ficavam três anos ou até definitivamente proibidos de se matricular em outra instituição de ensino superior; e foram centenas de matrículas negadas por ato dos Reitores. A partir de 1970 alguns estudantes recorrem a ações judiciais em defesa do direito de matrícula.

Ao tratar da relação entre adesão, resistência e acomodação, Motta (2014. P.288 e ss) ressalta que a resistência ao autoritarismo é tema fundamental nas representações dedicadas à ditadura brasileira, o que envolve 
batalhas de memória. Interessado mais em alcançar uma compreensão adequada do problema da resistência/colaboração nos meios acadêmicos, Motta conclui que a ditadura foi antes uma construção política considerada legítima por setores sociais significativos do que uma ocupação financiada por forças estrangeiras. Mas ressalta o protagonismo que os estudantes universitários tiveram como força de resistência. As manifestações de oposição ao regime militar foram retomadas por meio o uso da cerimônia de colação de grau como ato de protesto até a organização de shows e debates. A partir de 1976, os estudantes voltaram a ocupar as ruas, em atividades que adquiriram grande repercussão, o que manteve o governo militar sempre impopular entre os jovens universitários.

\section{CONSIDERAÇÕES FINAIS}

Para cumprir os objetivos deste estudo, cumpre enfatizar as relações necessárias desveladas entre Universidade, Juventude e resistência a partir dos aportes apresentados nos dois primeiros itens e nos relatos de memória que foram referidos no item três. Quanto às perguntas de partida, é possível concluir que sim, historicamente, Universidade e juventude se implicam mutuamente, e uma crise que atinge a população jovem de uma sociedade deve ser considerada como uma crise que atinge a Universidade e, portanto, interessa diretamente à Universidade. O contrário também é verdadeiro: se a Universidade entra em crise, a população mais diretamente afetada é a juventude e quaisquer decisões no seu âmbito, seja de organização administrativa ou de conteúdo metodológico, são decisões que afetam a juventude. Os períodos de recessão econômica sempre instalam questões envolvendo o papel do Estado e o tamanho das contas públicas, e a questão da sobrevivência de um modelo de Universidade pública no Brasil se torna central. Em períodos de austeridade, a preocupação com a administração e orçamento tende a tornou-se mais importante que as discussões de questões didáticas e metodológicas e o protagonismo das Universidades públicas brasileiras na produção de conhecimento e garantia da soberania.

Diante dessas conclusões, o olhar de expectativa que se volta para a juventude brasileira, em um cenário de ensino superior dominado (com cerca de $80 \%$ da oferta de vagas) pela iniciativa privada, desvela a imperiosa necessidade de discussão acerca das chances de permanência do projeto de Universidade pública no Brasil. Isso porque a Universidade foi aqui apresentada como um locus de preservação, mas também de modificação e rupturas com paradigmas do conhecimento adquirido e transmitido. Um conhecimento que orienta a ação e formata o comportamento na medida em que se empenha em ofertar um sentido de mundo para uma comunidade de pessoas.

Embora mantenha um legado significativo do medievo europeu no qual se constituiu, a Universidade preserva a capacidade de ser reconhecida socialmente como uma instituição capaz de promover transformações. 
Diante de toda a herança apontada, a Universidade acumula uma série de compreensões de si, e cada uma delas pode, oportunamente, se manifestar: como conservadora da ordem, como formadora do sujeito, como libertadora e emancipatória do espírito. Como no Brasil a Universidade se instala tardiamente, a questão da consciência de si não a afetou de modo profundo. O discurso "científico" já havia se instalado na "inteligência" brasileira. Talvez a principal característica dessa instalação tardia e invertida seja a relação tensa que muitas vezes se instala entre uma estrutura de Reitoria e Pró/Vice-Reitorias e as unidades acadêmicas, que decorre mais da reunião de unidades acadêmicas antes isoladas e autônomas sob uma gestão unificada.

Por sua vez, a ideia de juventude se constituiu entre a noção de grupo instável e perigoso e símbolo de futuro e renovação. Juventude significa um estado psíquico de comprometimento maior com o sentimento amplo em relação à capacidade de mudar a sociedade. Forças Armadas, Partidos políticos e Igrejas são exemplos de organizações que reservam um tratamento todo especial à juventude. Assim também fizeram os movimentos de massas na instalação dos Estados Totalitários, e nisso assemelham-se a um movimento com força revolucionária.

Numa larga trajetória de compreensão, se há uma crise na juventude brasileira contemporânea, essa crise se desenrola, em parte, dentro dos campi universitários, nos quais parcela da juventude protagoniza seus primeiros atos de independência e vivem as primeiras experiências de liberdade, como estudantes. O maior movimento de resistência da universidade brasileira foi sem dúvida aquele contra a reforma universitária de 1968. Foi nas universidades brasileiras dos anos 1950 e 1960 que se forjou uma geração com consciência de seu papel político. A resistência, então, se projetou como conseqüência dessa consciência. Os estudantes repudiaram, de forma coerente, o novo modelo, que permitia a matrícula por créditos, desarticulando grupos, e permitindo as bases para a abertura ao ensino superior privado no Brasil. Uma resistência protagonizada por estudantes, ladeados por professores. Sempre será oportuna a construção da memória de resistência, especialmente diante de crises e dispersão política. O resistente consciente orienta sua ação de forma a tornar-se o dissidente político, nunca visto como inimigo, mas como sujeito apto a discernir e optar dentre os muitos rumos que os processos políticos podem seguir.

\section{UNIVERSITY, YOUTH AND RESISTANCE: A REPORT OF BRAZILIAN UNIVERSITY REFORM IN 1968}

\section{Abstract}

The article aims to investigate the necessary relations between the University and the youth, from the affirmation that University and youth are protagonists of social transformations, sometimes through acts of resistance. The article investigates the origins of the University in Medieval Europe to point out the original characteristics that still remains and the modifications that transformed the University. The article investigates the origins of the 
University in Brazil and the growth of a university population. Next, the research investigates the concept of youth established in the variation of dangerous segment and subject of rights. The research articulates the two concepts to rescue the resistance movement to the Brazilian university reform of 1968, in the context of the military government and the MEC-Usaid Agreements. It is a bibliographical and a memory research. It concludes that there is a necessary implication between university and youth, revealing that a crisis in the university can be cause and consequence of a crisis in the youth.

Keywords: University; Youth; Reform; Resistance; MEC-Usaid Agreement.

\section{REFERENCIAS}

ALMEIDA, Ângela Mendes de. A República de Weimar e a ascensão do nazismo. Coleção Tudo é História. São Paulo: editora Brasiliense, 1982.

BRAGA, Marco et al. Breve história da ciência moderna: convergência de saberes. 2 ed. Rio de Janeiro: Jorge Zahar, 2006. V.1.

BRASIL: NUNCA MAIS. Relatório da Arquidiocese de São Paulo. 7 ed. Petrópolis: Vozes, 1985.

COSTA, Emília Viottida.Globalização e Reforma Universitária: a sobrevivência do MEC-Usaid, em Brasil: história, textos e contextos. São Paulo: Unesp, 2015a.

Conversa com a autora, em Brasil: história, textos e contextos. São Paulo: Unesp, $2015 b$.

FONSECA NETO, Eduardo. Universidade: do Trivium-Quadrivium ao Ensino-Pesquisa-Extensão. São Paulo: Alexa cultural, 2007.

LE GOFF. Jacques. Para uma outra Idade Média: tempo, trabalho e cultura no Ocidente; 18 ensaios. Trad. Thiago de Abreu e Lima Florêncio e Noéli Correia de Melo Sobrinho. 3. ed. Petrópolis, RJ: Vozes, 2014.

GUILHON DE ALBUQUERQUE, J.A. O movimento estudantil e classe média no Brasil. GUILHON DE ALBUQUERQUE, J.A. et al. (coord.).Classes Médias e política no Brasil. Rio de Janeiro: Paz e Terra, 1977, pp. $117 / 144$.

LOTRINGER, Sylvère. Como foi inventada a teoria francesa, em AXT, Gunter e SCHULER, Fernando Luís (orgs.). Fronteiras do pensamento: ensaios sobre cultura e estética. Rio de Janeiro: Civilização Brasileira, 2010.

MARTINS FILHO, Antônio. História abreviada da UFC. Fortaleza: Casa de José de Alencar/Programa Editorial, 1996.

MATTOS, Débora Michels, OSÓRIO, Paulo Sérgio, TEIXEIRA, Regina. História, Juventude e Participação: condições, possibilidades e atuações, em WOLKMER, Antônio Carlos. VIEIRA, Reginaldo de Souza. Estado, política e direito: relações de poder e políticas públicas. Santa Catarina: UNESC, 2008.

MORAES FILHO, Evaristo de. O socialismo brasileiro. Brasília: Instituto Teotônio Vilela, 1998. (Coleção Pensamento Social-democrata). 
MORIN, Edgar. 1968-2008: o mundo que eu vi e vivi, em AXT, Gunter e SCHULER, Fernando Luís (orgs.). Fronteiras do pensamento: ensaios sobre cultura e estética. Rio de Janeiro: Civilização Brasileira, 2010.

MOTTA, Rodrigo Patto Sá. As universidades e o regime militar: cultura política brasileira e modernização autoritária. Rio de Janeiro: Zahar, 2014.

OLMO, Rosa Del. A América Latina e sua criminologia. Rio de Janeiro: REVAN, ICC, 2004. (Pensamento Criminológico, 9).

PAXTON, Robert.Anatomia do fascismo. Trad. Patrícia Zimbres e Paula Zimbres. São Paulo: Paz e Terra, 2007.

ROMANELLI, Otaíza de Oliveira. História da Educação no Brasil (1930/1973). 39 ed. Petrópolis, Rio de Janeiro: Vozes, 2013.

SAVAGE, Jon. A criação da Juventude: como o conceito de teenager revolucionou o século XX. Trad. Tatiana M. Rodrigues. Rio de Janeiro: Rocco, 2009.

Trabalho enviado em 29 de maio de 2017.

Aceito em 12 de setembro de 2017. 